\title{
Comunicação e sustentabilidade no esteio da cidadania: um estudo sobre a (des)articulação entre organizações na esfera pública
}

Communication and sustainability as a stay for citizenship: a study on the (de-)articulation between organizations in the public sphere

Comunicación y sustentabilidad en la base de la ciudadanía: un estudio sobre la (des)articulación entre organizaciones en la esfera pública

\section{Daniela Viegas}

- Mestre em Gestão Social, Educação e Desenvolvimento Local, pelo Centro Universitário Una (Belo Horizonte)

- Especialista em Gestão Estratégica de Marketing pela Universidade Federal de Minas Gerais (UFMG)

- Graduada em Comunicação Social pela Pontifícia Universidade Católica de Minas Gerais (PUC-Minas)

- Professora do Centro Universitário Una e da PUC-Minas

- Experiência em consultoria e desenvolvimento de projetos de comunicação e sustentabilidade

- danieladvc@yahoo.com.br

\section{Armindo dos Santos de Sousa Teodósio}

- Doutor em Administração de Empresas pela Escola de Administração de Empresas de São Paulo (EAESP) da Fundação Getúlio Vargas (FGV)

- Mestre em Ciências Sociais - Gestão de Cidades pela Pontifícia Universidade Católica de Minas Gerais (PUC- Minas)

- Bacharel em Ciências Econômicas pela Universidade Federal de Minas Gerais (UFMG)

- Professor do Programa de Pós-Graduação em Administração da PUC-Minas

- Pesquisador das áreas de Gestão Social e Ambiental, Políticas Públicas e Estudos Organizacionais

- Líder do Núcleo de Pesquisas em Ética e Gestão Social (Nupegs) do PPGA da PUC-Minas

- Interesses de pesquisa em organizações da sociedade civil, responsabilidade socioambiental de empresas, políticas públicas, democracia e cidadania e desenvolvimento sustentável

- E-mail: teodosio@pobox.com 


\title{
Resumo
}

Para compreender os desafios da construção de ações e políticas capazes de renovar as práticas sustentáveis, problematizam-se neste artigo as respostas aos dilemas do consumo construídas por atores da sociedade civil, do estado e do mercado. Esse esforço sugeriria a construção de articulações entre diferentes grupos para atender às demandas dos atores sociais, por meio da ação política e do exercício da cidadania. Percebe-se que a construção de discursos e práticas politicamente corretas nem sempre dá conta da complexa relação que envolve a comunicação e o meio ambiente na esfera pública.

\section{PALAVRAS-CHAVE: CONSUMO SUSTENTÁVEL • CIDADANIA • COMUNICAÇÃO • MOBILIZAÇÃO SOCIAL}

\begin{abstract}
To understand the challenges of building actions and policies capable of renewing the sustainable practices, relevance is given in this article to the answers to the dilemmas of consumption built by actors of the civil society, of the state and of the market. This effort would suggest the construction of articulations between the various groups to meet the demands of the social actors, by means of political action and of the exercise of citizenship. One perceives that the construction of discourses and practices that are politically correct cannot always cope with the complex relationship that involves the communication and the environment in the public sphere.
\end{abstract}

\section{KEYWORDS: SUSTAINABLE CONSUMPTION - CITIZENSHIP - COMMUNICATION • SOCIAL MOBILIZATION}

\section{Resumen}

Para comprender los desafíos de la construcción de acciones y políticas capaces de renovar las prácticas sustentables, se problematizan en este artículo las respuestas a los dilemas de consumo construidas por los actores de la sociedad civil, del estado y del mercado. Este esfuerzo podría sugerir la construcción de las articulaciones entre diferentes grupos para atender a las demandas de los actores sociales, por medio de la acción política y del ejercicio de la ciudadanía. Se percibe que la construcción de discursos y prácticas políticamente correctas ni siempre dan cuenta de la compleja relación que involucra a la comunicación y al medio ambiente en la esfera pública.

\footnotetext{
PALABRAS CLAVES: CONSUMO SUSTENTABLE - CIUDADANÍA - COMUNICACIÓN • MOVILIZACIÓN SOCIAL
} 
A repercussão pública sobre a questão ambiental tem movido governos, organizações da sociedade civil, empresas e cidadãos a se apropriarem da discussão da sustentabilidade, seja como um novo campo de ação, um elemento de regulação, uma exigência das formas de produção e consumo ou uma bandeira defendida no mundo. Percorrer as ruas de uma metrópole contemporânea contempla ouvir, ver e sentir a problemática ambiental saltar à percepção. Trata-se de uma expressão incorporada por atores sociais, que se tornou ideia-força no discurso e compõe o imaginário social.

Nesse cenário, uma das soluções apontadas é a transformação do modo de consumir, permitindo que os cidadãos tomem as decisões acertadas nos seus atos de consumo, adquirindo consciência do impacto coletivo, ambiental e social em que se traduzem suas opções de consumo para a promoção da qualidade de vida e do desenvolvimento. Por trás do suposto raciocínio consensual em torno do consumo politicamente correto, há interesses, disputas de poder e projetos díspares de organização social que se espelham na maneira de se interagir com o meio ambiente na dinâmica da sociabilidade contemporânea (Naves, 2004; Zhouri, Laschefski e Pereira, 2005).

O presente artigo, de natureza qualitativa, propõe problematizar a relação entre comunicação, cidadania e a sustentabilidade, tendo como referência o debate sobre o consumo sustentável. Como objeto de análise foram estudadas organizações que operam no campo do consumo, empresas de comunicação que atuam com projetos de mobilização social para a cidadania ambiental e órgãos do estado, nos seus três níveis, que desenvolvem políticas públicas no campo ambiental. A intenção é compreender os desafios da construção de ações e políticas capazes de renovar as práticas de consumo, de forma a torná-lo mais sustentável, problematizando-se a comunicação social e suas limitações.

\section{CONSTRUÇÃO DA CIDADANIA SOCIOAMBIENTAL}

No Brasil, alguns estudos indicam mudanças de postura da população em torno das questões ambientais. Pesquisa divulgada em 2006 pelo Ministério do Meio Ambiente e pelo Instituto de Estudos da Religião aponta que a conscientização do brasileiro em relação ao meio ambiente aumentou 30\% nos últimos quinze anos (Mendes, 2006). De acordo com o estudo, o aumento da consciência, no entanto, não é acompanhado de um crescimento das atitudes em prol do meio ambiente, sendo que o perfil do cidadão mais preocupado é ainda o de alta escolaridade e renda e morador de centros urbanos.

Esse dado é confirmado pela pesquisa nacional de opinião "O que o brasileiro pensa do meio ambiente", realizada por Samyra Crespo (2002) em uma série histórica comparativa entre os anos 1992, 1997 e 2001. O estudo revela que o nível de informação pouco evoluiu, considerando tanto os problemas ambientais locais quanto os mundiais. As variáveis que fazem diferença quanto à conscientização são a educação e a residência em centros urbanos. 
Os resultados indicam que a população brasileira vem incorporando práticas de consumo que levam em consideração outros atributos que não exclusivamente preço e qualidade dos produtos. Porém, como aponta Crespo (2002), ainda há muito que avançar, principalmente porque os resultados da pesquisa conduzem a uma questão mais estrutural. Ao analisar o nível de escolaridade dos entrevistados que não souberam opinar e não apontaram nenhum problema ambiental no seu bairro, observou-se que, quanto menor o nível de instrução, maior a dificuldade em apontar problemas.

Desta maneira, o tema do consumo deveria perpassar a dinâmica estrutural das sociedades, alterando-se a forma de conceber e de agir coletivamente. Boaventura de Sousa Santos (2002) destaca que, no Brasil, o crescimento econômico, baseado na racionalidade econômica, sustentou o modelo político e cívico. O conceito de cidadania desenvolvido, portanto, seria distante da consciência de pertencimento em relação à coletividade. Em lugar do cidadão formou-se o consumidor, em um modelo de cidadania desigual.

Perspectivas como "o fim da cidadania" (Zygmunt Bauman", "o declínio do homem público" (Richard Sennet), "a dissolução do espaço público" (Hannah Arendt) ou "o esgotamento das energias utópicas (Jürgen Habermas) conduzem à percepção de que os cidadãos teriam sido reduzidos à condição de consumidores. No ato do consumo, os sujeitos centralizariam suas decisões, não se preocupando com os impactos que suas escolhas poderiam gerar (Portilho, 2005).

A noção de cidadania contemporânea significa um processo de aprendizado social e de construção de formas de relações sociais e práticas políticas concretas. Assim, pode-se avançar a um novo quadro de referência para as práticas de consumo. Vários autores confrontam a ideia de que o consumo compõe uma arena privada e despolitizada. Néstor García-Canclini (1996) defende que, a partir da deterioração da política e da descrença nas instituições são criadas outras formas de participação política e de identidade cultural, sendo o consumidor um ator social crítico. $O$ autor sugere um encontro do consumo e da cidadania, percebendo-os como práticas sociais que geram sentido de pertencimento. $O$ mercado seria não somente um espaço de troca de mercadorias, mas parte de interações socioculturais complexas, pois o consumo não significaria apenas posse individual de objetos, mas apropriação coletiva, oferecendo possibilidades de formação de "consumidores-sujeitos-cidadãos", vivificando as oportunidades para a cidadania se fortalecer nas ações cotidianas, como práticas de consumo (Portilho, 2005).

Para Kathleen M. Blee (1985), em certos contextos, o consumo pode se tornar uma transação politizada, à medida que incorporaria a consciência das relações de poder envolvidas nos processos de produção e promoveria ações coletivas na esfera pública. Essas reflexões reconfigurariam as formas de sociabilidade, identidade e ação política.

Fátima Portilho (2005) defende que são escassas as produções sobre a formulação de políticas públicas para fazer avançar o consumo sustentável. Pode-se ponderar que a politização do 
consumo seria uma extensão das novas configurações das práticas públicas. Se uma das propostas para alcançar o desenvolvimento sustentável é a modificação dos padrões e formas de consumo, os consumidores - cidadãos - podem edificar maneiras de participação política e fortalecer a cidadania e o interesse pelo espaço público.

O reforço aos contornos da democracia direta, o incentivo à participação cidadã na definição das políticas estatais e a possibilidade de deliberação pública compõem os marcos da noção de democracia participativa, bem como a sustentação de um sistema institucional relativamente aberto para permitir a experimentação. Dessa maneira, a participação indicaria o fortalecimento e a democratização da sociedade e do estado, assim como a redefinição das relações entre ambos. Pedro Pontual e Carla Silva (1999) mencionam a necessidade de o cidadão repensar seu papel na "cogestão local", transformando os canais de participação em espaços de discussão e debate de políticas públicas e explicitação de conflitos e interesses (Avritzer; Pereira, 2002).

As noções de cidadania e de participação popular são apontadas como primordiais para a minimização das desigualdades sociais e condução de um desenvolvimento que aspire a ser sustentável (Acselrad, 2001), sem deixar de sopesar os dilemas para a sua edificação no tecido social brasileiro. Na visão de Rocío Castro (2006), as disparidades sociais e a destruição ambiental são os motivos da diminuição da qualidade de vida do exercício da cidadania. A questão ambiental teria originado uma nova agenda de direitos para a sociedade, incluindo o direito a um meio ambiente equilibrado como componente da cidadania, como direito difuso e coletivo. A propagação da questão ambiental e o papel dos movimentos ambientalistas e das organizações da sociedade civil na luta pelos direitos ambientais, a partir da década de 1970, teriam contribuído para a construção de uma cidadania ambiental no Brasil (Silva-Sánchez, 2000, p. 13).

Com efeito, a formação de uma cidadania ambiental no Brasil comporia um processo mais vasto de reconstrução da sociedade, a partir da manifestação de setores organizados, com capacidade de intervir e participar das decisões políticas. Nesse sentido, o próprio reconhecimento da crise ambiental atual demonstra como o meio ambiente é percebido. Nos últimos anos essa questão ganhou centralidade nos debates sociais, demonstrando a dimensão do meio ambiente como construção social, que também contempla as representações sociais sobre os dilemas ambientais e os interesses envolvidos (Naves, 2004). De acordo com André Zhouri, Klemens Laschefski e Doralice Pereira (2005), vem ocorrendo certa propagação da crença de que esses conflitos que cercam a questão ambiental poderiam ser resolvidos por meio da gestão do diálogo entre os atores para atingir o consenso. Dessa forma, a variável ambiental teria sido incorporada ao discurso dos desenvolvimentistas.

Cornelius Castoriadis (1981, p. 130) confirma a perspectiva ao dizer que a crise ambiental é também uma crise de "postulados e das significações imaginárias correspondentes". A atuação frente ao sistema conduzida pelos sujeitos é simbólica e permeada por valores, que 
direcionam os sentidos e a compreensão coletiva sobre o meio ambiente, exigindo uma redefinição das formas de se pensar a realidade. Para Zhouri, Laschefski e Pereira (2005), o empenho em envolver os atores locais em programas de caráter desenvolvimentista e, mais atualmente, de cunho socioambiental, relaciona-se às tentativas de considerar uma das perspectivas do desenvolvimento sustentável, ou seja, como afirma Barbieri (1997, p. 128, apud Zhouri, Laschefski e Pereira, 2005, p. 66) "um dos pré-requisitos fundamentais para se alcançar um desenvolvimento sustentável é a ampla participação pública nos processos de tomada de decisão".

Nesse cenário, a entrada do meio ambiente no campo da política, para Isabel de Moura CarvaIho (2006), ampliaria a esfera pública e formaria cidadãos ecológicos, que seriam antes sujeitos políticos em defesa de uma sociedade emancipada e sustentável. Como afirma Régia Cristina Oliveira (2005), cada vez mais o campo ambiental vem sendo instituído na esfera pública como bem comum. Ele alcança posição de destaque no debate sobre as condições das gerações futuras, fazendo com que haja permanentes negociações entre as esferas pública e privada. Isso permite aos cidadãos a oportunidade de adquirir experiência política para a atuação social, com o objetivo de promover o desenvolvimento local.

No entanto, se parece ser apressado assumir uma visão fatalista ou criticista quanto ao consumo nas sociedades contemporâneas, também merecem estudos mais complexos e profundos as perspectivas que anunciam avanços nas lutas ambientais. Perduram importantes dúvidas sobre a materialidade da cidadania socioambiental em sociedades, como a brasileira, que parecem ser cada vez mais assoladas pelo consumo desenfreado. Esse contexto indica a necessidade de se problematizar a ação de movimentos sociais no campo do consumo sustentável, desvelando suas ações, escolhas, caminhos e descaminhos na trilha em direção ao desenvolvimento que respeite o meio ambiente, espaço de sociabilidade no qual se descortinam dramas e tramas do politicamente correto na contemporaneidade.

\section{SUSTENTABILIDADE E COMUNICAÇÃO NO CONFRONTO DE DISCURSOS}

Para definir a visão de sustentabilidade e como essa prática pode se tornar mais efetiva, foi realizado um estudo de natureza qualitativa, com roteiro semi-estruturado para as entrevistas em profundidade, que foi pré-testado na intenção de verificar possíveis dissonâncias. Após a validação, foram realizadas entrevistas em profundidade com três grupos, centrando a abrangência da coleta de dados primários em Belo Horizonte, campo de delimitação desta pesquisa. Totalizaram-se nove entrevistas, três com cada grupo: estado, organizações da sociedade civil e empresas de comunicação.

O primeiro grupo de entrevistados foi composto por três executivos de empresas de comunicação e marketing que atuam no mercado de Belo Horizonte, seja desenvolvendo projetos para empresas locais ou de outros estados. Essas empresas foram selecionadas por 
se constituírem em referência no segmento de comunicação mineiro e por terem desenvolvido ações socioambientais para seus clientes, tais como criação de campanhas em prol do meio ambiente e políticas de atuação socioambiental, entre outras. Todos os entrevistados foram da alta administração, considerados aptos a responder pela visão global da empresa.

O segundo grupo de entrevistados foi composto por três organizações não-governamentais que atuam no campo do consumo, com ações voltadas para as questões ambientais e para a mobilização social. Três órgãos do poder público relacionados ao consumo e meio ambiente foram entrevistados, nos níveis municipal, estadual e federal. Os entrevistados foram executivos com cargos de coordenação de mobilização social e programas de educação e sustentabilidade.

O terceiro grupo investigado foi composto por três representantes de órgãos públicos que lidam com a temática ambiental e do consumo - mesmo que implicitamente -, nos três âmbitos do estado: municipal, estadual e federal. Foram entrevistados representantes da Superintendência de Limpeza Urbana de Belo Horizonte (SLU - Belo Horizonte), da Secretaria de Estado de Meio Ambiente e Desenvolvimento Sustentável de Minas Gerais (Semad - Belo Horizonte) e da Agência Nacional de Águas (ANA - Brasília).

As entrevistas buscaram compreender o conhecimento e a articulação de ideias sobre sustentabilidade, além da relevância do trabalho de comunicação para a mobilização social. Elas foram presenciais, duraram em média uma hora e trinta minutos, foram gravadas com consentimento dos respondentes e transcritas na íntegra. A coleta de dados foi efetivada em janeiro de 2010. Todos os respondentes preencheram o "perfil dos participantes", com dados demográficos e socioeconômicos para a análise.

Um paralelo das entrevistas dos três grupos de atores pesquisados - estado, empresas de comunicação, organizações da sociedade civil - é apresentado a fim de problematizar as questões relativas à sustentabilidade e à comunicação. Isto é, a partir da reflexão sobre a construção que esses públicos entrevistados formam sobre o consumo sustentável, a transformação dos atos, a comunicação e a mobilização social, pretendeu-se analisar como a comunicação se manifesta no consumo, de que maneiras os atores sociais constroem o seu campo de atuação e suas formas de participação social e como esses fatores afetam a sustentabilidade. Com base no referencial teórico pesquisado, buscou-se identificar se há e como se desenha a contribuição da área de comunicação para a mobilização social e identificar possibilidades de atuação no âmbito do consumo sustentável em Belo Horizonte.

\section{Desafios da relação entre consumo, sustentabilidade e participação popular}

A partir das entrevistas e análises realizadas, alguns indicativos para superar os problemas sociais e ambientais relacionados ao consumo são apresentados, em uma perspectiva de interação e interdependência dos fatores, de forma que, se um deles não operar, os demais 
ficariam enfraquecidos. O primeiro desses fatores, na visão dos três grupos de entrevistados, seria a educação, ampliada, igualitária e de qualidade a toda a sociedade, base para a garantia de acesso à informação, o segundo pilar apresentado. A falta de disseminação das informações seria um fator dificultador tanto para a baixa participação da sociedade nas decisões e ações voltadas para a sustentabilidade quanto para a postura crítica e de cobrança que se absteriam de assumir, afastando-se da posição de protagonistas e formadores de cidadania.

Aliado a esses dois fatores, estaria a questão da maturação do tempo para se verificar alguma mudança na conduta dos indivíduos, considerando que desde a sua sensibilização até sua efetiva mudança de atitude levaria um certo tempo. Essa questão representaria outro dilema: o fator mobilizador seria individual, ou seja, cada pessoa passaria por um processo de transformação diferente, sendo o indivíduo sensibilizado e partindo para a ação motivado por fatores que lhe são muito peculiares.

Um terceiro fator considerado dilema dentro das questões do consumo e do meio ambiente seria a ausência de uma legislação específica relacionada ao consumo sustentável, acompanhada por fiscalização da conduta dos atores. A legislação abarcaria todos os segmentos sociais, indicando diretrizes de atuação responsável e punição dos infratores, sejam eles empresas, estado, organizações da sociedade civil ou cidadãos.

Outro problema a ser vencido seria o fato da concentração das discussões nas esferas científica e técnica, cenário que não inclui grande parcela da sociedade nos debates e, consequentemente, decisões dentro do campo do consumo sustentável. O cidadão sentiria dificuldade em participar ou se fazer representar.

Para os entrevistados, na perspectiva brasileira, há constatação de um início de mudança da percepção dos cidadãos quanto à sustentabilidade, mas não se verifica alteração de hábitos de consumo e prática de um padrão mais sustentável. Possivelmente se relacionaria a esse fato a questão de que a consciência dos cidadãos teria que estar acompanhada de investimentos em infraestrutura nas cidades para garantir uma atuação mais sustentável. Muito além desses fatores estaria a reflexão sobre a modificação da lógica do consumo, elevando a sociedade a um outro patamar de organização social, o que sugeriria um outro nível de articulação entre as esferas do mercado, do estado e da sociedade.

\section{Comunicação, cidadania e mobilização social}

De acordo com os três grupos de entrevistados, a comunicação social figuraria como um pilar em desenvolvimento dentro da trama da sustentabilidade. Os indícios apontam que ela seria um fator relevante na mobilização social, desde que garanta informação independente, adaptada 
ao público receptor e de qualidade aos cidadãos, ajudando no engajamento dos atores. Ressalta-se que esse fator, desconexo e isolado, não traria garantia de mobilização de atores em função de uma causa, mas a sua articulação com outros estímulos como a educação ambiental e cidadã e a formulação de uma legislação adequada poderiam contribuir para a melhoria da participação popular e edificação da cidadania.

Além disso, colaboraria para o baixo nível de participação e engajamento a falta de um movimento geral a favor da sustentabilidade, o que levaria à desmotivação da mudança individual. Esse desafio poderia começar a ser superado por meio da divulgação expressiva de boas práticas na sustentabilidade, além de incentivar atores representativos da sociedade a 'darem o exemplo', sejam eles governantes, autoridades ou personalidades, tanto de nível nacional quanto local.

A pesquisa apontou que dar escala e velocidade a essa comunicação seriam grandes desafios para a ciência da comunicação, em uma discussão em que os meios convencionais de informação e relacionamento com a sociedade dão a impressão de não terem tanta eficácia na sensibilização e captação da atenção dos sujeitos.

O discurso atualmente praticado por empresas, estado e organizações da sociedade civil parece não convencer os cidadãos para mudança de suas atitudes no consumo, sendo necessária a reflexão sobre meios e formas de comunicação e interação com a sociedade que possam encantar e despertar os cidadãos para a ação social. A formação de um espírito emotivo por meio da comunicação, longe de representar uma única via de atuação, poderia contribuir para a sensibilização dos atores para a reflexão sobre seus hábitos, desde que se afaste das armadilhas da propaganda hipnótica praticada no sistema capitalista. A comunicação libertadora caminharia para conduzir à reflexão e não a uma definição de padrões pré-definidos de atuação no consumo.

Nesse sentido, na impossibilidade de se realizar uma comunicação individual a cada cidadão, a comunicação tenderia a ser direcionada aos grupos de atores, já que a mudança de conduta no consumo tem se mostrado muito particular, isto é, cada pessoa seria impactada a partir de um determinado estímulo. O conteúdo da comunicação para a mobilização social, diferentemente do que se pode observar em alguns exemplos atuais, sugere ter mais efetividade quando se afasta do extremismo, da acusação e responsabilização dos sujeitos pelos problemas sociais e ambientais. A mensagem tende a se fixar e repercutir em ações do indivíduo quando é aliada a um reforço prático da mobilização, colocando o indivíduo para agir a partir do que recebeu como informação.

Segundo Murilo C. Ramos (2005), a informação, na forma de liberdade de pensamento e de expressão, enquanto insumo vital para a cidadania, faz parte dos direitos humanos e constitui um prolongamento do avanço em direção à democracia. Isso pressupõe a comunicação em dupla direção - emissor e receptor - em um intercâmbio de informações e possibilidades de acesso e participação dos sujeitos. Esse sistema compreenderia o fornecimento de meios mais 
numerosos e variados a um maior número de pessoas. Significaria também possibilidades para as nações, forças políticas, comunidades, entidades e grupos sociais - de relacionamento em um plano de igualdade, sem domínio dos elementos mais fracos e sem discriminações. Resumidamente, provocaria mudanças de perspectiva.

Cidadãos informados e com condições de analisar criticamente os acontecimentos dependeriam de uma imprensa ética e preocupada com os anseios dos atores da esfera pública. Nesse sentido, discute-se o papel da imprensa para a transmissão de informações. O espaço de visibilidade criado pelos meios de comunicação, embora marcado por densas assimetrias na estruturação da comunicação dos diferentes atores sociais, contribuiria para a promoção de um diálogo público. Wilson Gomes e Rousiley Maia (2008) discutem que, embora os meios de comunicação tenham tomado grande função midiática na contemporaneidade, conservariam ainda a capacidade de formação da opinião, sendo possível realizar crivo entre as posições apresentadas na cena midiática. A crítica à limitação dos meios de comunicação, nesse sentido, é aceitável, já que a exaustão da argumentação realmente não seria da abrangência dos meios, prova de que a discussão política acontece também fora da situação midiática. A comunicação e a argumentação se expandem muito além dos muros da mídia. A partir da publicização, transparente e imparcial, de uma matéria jornalística, os sujeitos são convocados a interpretar seu conteúdo, a partir de sua bagagem cultural, em uma manifestação que dependeria da ação independente e livre dos indivíduos, que pode ou não acontecer.

As discussões e análises não seriam propriedade ou exclusividade da cena midiática, como se ela conseguisse abarcar toda a complexidade da esfera pública. Pelo contrário, a noção de argumentação pública ou de intercâmbio de opiniões, razões e expectativas constitui fundamentalmente o cerne da esfera pública. Ao citar Habermas, os autores Gomes e Maia (2008) reafirmam que a discussão pública possui determinadas condições que a esfera midiática não seria total e automaticamente capaz de atender.

Uma comunicação continuada, ininterrupta, poderia oferecer maior garantia de permanência de uma conduta de consumo mais sustentável, ao isolar a possibilidade de uma atuação pontual, tal como a compra de um produto menos poluente uma única vez ou a realização isolada de um evento comunitário sustentável.

Para aproximar-se de uma mobilização ética e transformadora, a comunicação para a articulação das pessoas em favor de uma causa primaria, nessa fronteira de raciocínio, por

uma ação transformadora, baseada em uma mobilização com emoção, mas sem manipulação. É preciso considerar a ótica dos diferentes públicos, adaptar as mensagens a essa ótica e aos meios disponíveis para disseminá-la, posicionando o receptor no centro da comunicação (Soares-Baptista, 2006, p. 51). 
Antes de garantir que à comunicação pertenceria o poder de mobilizar cidadãos, é preciso refletir sobre as possíveis armadilhas que os complexos sistemas comunicacionais podem construir, já que esse tipo de comunicação, voltada para a sustentabilidade ou para causas sociais, busca sensibilizar corações e mentes e transformar o mundo, objetivos facilmente aceitos e bem vistos pela sociedade. Em uma primeira análise, um dilema estaria na questão de que a comunicação priorizaria questões técnicas - o que funciona melhor, como aprimorar a comunicação e a formação de redes eficazes - em detrimento de um posicionamento de dotar o cidadão da capacidade de reflexão sobre seus atos (Sovik, 2006).

A comunicação também procura pesquisar e compreender a estrutura dinâmico-emocional da vida coletiva, entendendo os seus valores e modo de pensar, de maneira a minimizar as resistências às suas mensagens. No entanto, ao se realizarem as ações e campanhas de comunicação, o público é pensado como um conjunto. Na visão de Liv Sovik (2006, p. 07), "esse tipo de comunicação é importante quando se tem uma mensagem clara e inquestionável, mas não é uma solução se as resistências do público são razoáveis e precisam ser reconhecidas ou negociadas politicamente", como seria o caso da sustentabilidade, que ainda está em discussão no espaço público.

Outra armadilha estaria no fato de que estrategistas de comunicação, ao se sentirem conhecedores da realidade social, elaboram e desenvolvem ações pretensamente válidas, articulando interesses econômicos ou políticos em torno de uma proposta e deixando de interpelar os cidadãos daquele determinado local ou comunidade. Raras são as iniciativas que envolvem os sujeitos nos processos comunicacionais, em uma visão endógena de desenvolvimento das práticas de comunicação efetivas. Para Sovik (2006), a finalidade desse processo não seria o atingimento do público-alvo pelo conteúdo da campanha, mas a ação coordenada e eficaz por parte desse público em função de uma causa social ou ambiental que lhe é própria.

Sovik (2006, p. 08) coloca em cheque a capacidade da comunicação, tal como é utilizada atualmente, para lidar com questões sociais complexas: "Como é regra da comunicação publicitária não ofender (embora possa provocar), mas vencer pela atração e insistência, ela não é a melhor forma de enfrentar relações sociais complexas". Dessa maneira, a comunicação poderia ser considerada mais discurso que ação. E, enquanto discurso, dissipar-se-ia facilmente. Assim, a comunicação deveria estar sempre aliada a um conjunto de outras ações, de forma planejada e contínua, não devendo se considerar central nos processos sociais, mas atuar de forma colaborativa.

Jürgen Habermas (1988) enfatiza o poder social integrador e emancipatório dos processos comunicativos, localizando-o nas interações comunicativas. A comunicação seria a forma pela qual a cultura seria transmitida, forma de integração social e de socialização, por meio da qual se adquiririam identidades coletivas e individuais. Para contribuir com a difusão da sustentabilidade, a comunicação precisa de preocupação efetiva com os impactos socioambientais que sua produção e seu consumo geram. 
O movimento pela sustentabilidade tem atraído atores dos diversos segmentos da comunicação social para realizar discussões e já é possível perceber que existem iniciativas tentando canalizá-lo para um patamar mais construtivo e benéfico. Todavia, sem o reconhecimento dos limites da efetividade da comunicação será difícil avançar na concepção de uma comunicação ética, empoderadora e mobilizadora, a serviço da sociedade.

\section{CONSIDERAÇÕES FINAIS}

As incertezas sobre a ampliação da esfera pública e formação de cidadãos ecológicos com a entrada do meio ambiente no campo da política merecem estudos mais complexos sobre as perspectivas que anunciam avanços nas lutas para a sustentabilidade. Perduram importantes dúvidas sobre a materialidade da cidadania socioambiental em sociedades, como a brasileira, que parecem ser cada vez mais assoladas pelo consumo desenfreado.

A partir dos estudos realizados, propõe-se a reflexão de que a elaboração e implementação de políticas públicas voltadas à sustentabilidade implicam desafios, demandando a articulação entre instâncias do estado, da sociedade civil, do mercado e da esfera da vida privada. A estruturação dessas políticas precisa considerar as necessidades das populações que pretendem atender. A intersetorialidade pode ser uma opção viável, podendo gerar maior eficiência na aplicação de recursos e no desenvolvimento das próprias políticas públicas.

Por meio da análise da experiência no campo da sustentabilidade desenvolvida pelos atores pesquisados, percebe-se que a construção de discursos e práticas politicamente corretas no consumo, para torná-lo ambientalmente correto, nem sempre dá conta da complexa relação que envolve o meio ambiente na esfera pública. Nesse contexto, descortinam-se diferentes dramas e tramas da cidadania socioambiental e da comunicação para a mobilização social, que podem dar novo sentido às lutas ambientais, bem como encobrir as armadilhas que um discurso ambientalmente correto, mas politicamente frágil, carrega no contexto local.

De acordo com a pesquisa de campo, a comunicação, como um instrumento de mudança social, ainda precisa superar decisivos dilemas, como o posicionamento contraditório dos meios de comunicação, que ora veiculam programas de educação ambiental, ora transmitem comerciais consumistas; a pulverização dos canais de acesso ao consumidor, que atualmente ultrapassam os básicos anúncios comerciais e modificam formatos e linguagens para que a mensagem chegue adaptada a nichos diferentes de consumidores; a ocorrência de certo mascaramento ou, como também denominado, "maquiagem" dos acontecimentos em organizações, o que faz com que pequenas ações se transformem em grandes acontecimentos empresariais.

A pesquisa mostrou que a especificidade do trabalho de comunicação para a mobilização social não permite generalizações, visto que cada grupo de sujeitos é sensibilizado por um tipo de 
interação comunicacional. Para compreender os desafios da construção de ações e políticas capazes de renovar as práticas de consumo, de forma a torná-lo mais sustentável, problematiza-se a comunicação social e suas limitações, além de consistir em tarefa extremamente complexa isolar esse fator dos demais em um processo de mobilização. Variáveis como o contexto da comunicação, o canal utilizado e o universo cultural e simbólico dos sujeitos são elementos que interferem na sensibilização. As tentativas de comunicação são tão recentes que ainda não se conseguiu verificar consistentemente qual o nível de contribuição das ações de comunicação para avançar na transformação de atitude por parte dos cidadãos. Essa realidade justifica novas investigações e análises, capazes de entender como e por que os diferentes atores convergem (ou não) suas ações em direção à sustentabilidade.

\section{REFERÊNCIAS}

ACSELRAD, Henri. Políticas ambientais e construção democrática. In: VIANA, Gilney; SILVA, Marina; DINIZ, Nilo (Org.). O desafio da sustentabilidade: um debate socioambiental no Brasil. São Paulo: Fundação Perseu Abramo, 2001. p. 75-96.

AVRITZER, Leonardo; PEREIRA, Maria de Lourdes. Democracia, participação e instituições híbridas. Belo Horizonte: DCP/Nupass, 2002.

BLEE, Kathleen M. Family patterns and the politicization of consumption. Sociological Spectrum, v. 5, n. 4, p. 295-316, 1985.

CARVALHO, Isabel C. de Moura. As transformações na esfera pública e a ação ecológica. Revista Brasileira de Educação. v. 11 , p. 308-315, 2006.

CASTORIADIS, Cornelius. Reflexões sobre o desenvolvimento e a racionalidade. In: Revolução e autonomia: um perfil de Cornelius Castoriadis. Belo Horizonte: Copec, 1981. p. 117-147.

CASTRO, Rocío (Org.). Participação cidadã no meio rural: análise dos conselhos municipais no âmbito do Projeto Prorenda/DLS Bahia. Salvador: GTZ, Ciags/UFBA, 2006.

CRESPO, Samyra. (Coord.). O que o brasileiro pensa do meio ambiente e do desenvolvimento sustentável. Rio de Janeiro: Iser / Ministério do Meio Ambiente, 2002.

GARCÍA-CANCLINI, Néstor. Consumidores e cidadãos: conflitos multiculturais da globalização. Rio de Janeiro: Editora UFRJ, 2006. 227 p.

GOMES, Wilson; e MAIA, Rousiley C. M. Comunicação e democracia: problemas \& perspectivas. São Paulo: Paulus, 2008.

HABERMAS, Jürgen Teoria de la acción comunicativa: Tomo II. Crítica de la razón funcionalista. Madrid: Taurus, 1988.

MENDES, Daniela. Pesquisa mostra crescimento da consciência ambiental no Brasil. Ambiente Brasil, 2006. Disponível em: <http://noticias.ambientebrasil. com.br/clipping/2006/05/22/24797-pesquisa-mostra-crescimento-da consciencia-ambiental-no-brasil.html>.

NAVES, Flávia Luciana Saberes, poderes e os dilemas das relações socioambientais. Organizações Rurais e Agroindustriais, Lavras (MG), v. 6, n. 2, p. 121-133, jul.-dez. 2004.

OLIVEIRA, Régia Cristina. Juventude e sociedade: trabalho, educação, cultura e participação. Tempo soc., v. 17, n. 2, p. 386-392, nov. 2005. 
PONTUAL, Pedro; SILVA, Carla. Participação popular nos governos paulistas: trajetórias mecanismos e caráter. In: MAGALHÃES, Inês; BARRETO, Luiz; TREVAS, Vicente. Governo e cidadania: balanço e reflexões sobre o modo petista de governar. São Paulo: Fundação Perseu Abramo, 1999. p. 61-71.

PORTILHO, Fátima. Sustentabilidade ambiental, consumo e cidadania. São Paulo: Cortez, 2005.

RAMOS, Murilo C. Comunicação, direitos sociais e políticas públicas. In MARQUES DE MELO, José; SATHLER, Luciano Direitos à comunicação na sociedade da informação. São Bernardo do Campo, SP: Umesp, 2005.

SANTOS, Boaventura de Sousa; RODRÍGUEZ, César. Introdução: para ampliar o cânone da produção. In: SANTOS, Boaventura de Sousa (Org). Produzir para viver: os caminhos da produção não capitalista. Rio de Janeiro: Civilização Brasileira, 2002. p. 23-77.

SILVA-SÁNCHEZ, Solange S. Cidadania ambiental. São Paulo: Humanitas / FFLCH-USP, 2000.

SOARES-BAPTISTA, Rozália Del Gáudio. A construção simbólica do terceiro setor. In: PIMENTA, Solange M.; SARAIVA, Luiz A. Silva; e CORREAA, Maria Laetitia (Org.). Terceiro setor: dilemas e polêmicas. São Paulo: Saraiva, 2006. p. 41 a 63.

SOVIK, Liv. A alma das empresas: marketing e ativismo social. Revista Democracia Viva, n. 33, p. 03-08, out. -dez. 2006.

ZHOURI, André; LASCHEFSKI, Klemens; PEREIRA, Doralice B. Desenvolvimento, sustentabilidade e conflitos socioambientais. In: ZHOURI, Andréa; LASCHEFSKI, Klemens; PEREIRA, Doralice B (Org.). A insustentável leveza da política ambiental. Belo Horizonte: Autêntica, 2005.

Recebido em: 03.09.2012 / Aceito em: 11.03.2013 